\title{
Research of the Application of Data mining in Bank Personal High Quality Customer Management
}

\author{
Zhang Yi \\ Nanchang Normal University \\ Department of Mathematics and Computer Science
}

\begin{abstract}
With more and more foreign financial institutions entering Chinese market, financial industry will face more competitions in fighting for high quality customers and expanding market share of new business. How can financial industries find the most effective customers and how to develop a competitive business, "data mining" technology arises at the historic moment. The value of the application of data mining technology is to help financial enterprises analyze the key factors that affect their business, then to help financial enterprises increase revenue, reduce costs, and to make the decision-making of financial industry management be more scientific and customer analysis be more accurate. This paper introduces the data mining and data preprocessing and carries out the application research of the personal quality customer management based on data mining technology.
\end{abstract}

Keywords-Customer relationship management; Data mining; Banks

\section{INTRODUCTION}

In recent years, various commercial banks of China pay much attention to the personal business development and have established special personal business management department and (personal) customer manager system, put forward the business philosophy "taking the personal business as a new profit growth point", and actively explore new development ideas. In terms of individual users, commercial banks have formed a complex competition situation.

Customer relationship management implements the idea that "taking the customer as the center", which represents the sum of the theories, methods, technologies, abilities and software which are used by enterprises to develop long-term cooperation relationship with customers and to improve the operating performance of enterprise to take customers as the center. A real and mature CRM solution can help enterprises improve the abilities of seizing the essence of problems as a whole and making the correct responses in decision-making process. Through the perfect customer service and in-depth analysis of customers, it meets customers' demands and ensures the realization of customers' lifetime value. This paper analyzes and practises the research of the application of data mining in bank personal quality customer management.

\section{THE PRESENT SITUATION OF CUSTOMER MANAGEMENT SYSTEM OF BANKS IN CHINA}

Customer management is one of the most important steps of the survival of banks. For banks with large customer data, customer management information based on data mining technology is becoming more and more important, so wise banks will not discard any job related to this, because the ones who have mastered the most advanced customer information technology will win the market. Many famous banks, such as Morgan Bank, Citibank, FCC State Bank, HSBC and UBS have adopted the most advanced customer management system based on data mining and get a lot of benefits.

Citibank obtained extraordinary development in the past 20 years. The former President of Citibank attributed their success to that Citibank effectively used management information system based on customer data mining which can efficiently identify the level of 
customers (especially key customers) in the large amount complex data by combining with computer technology, then make decision about the acquisition and retention of customers and quickly choose the right strategies according to different customer requirements, which can optimize and raise the level of banking services and maximize the bank efficiency and benefits.

In banks of China at present, although banks establish investment with large scale in terms of data management system, except a handful of banks, the data management systems of the most banks are still in low level and have a big gap comparing to the banking systems of developed countries in the world in computer technology, management and use of customer data. The establishment of the system is not only lacking of overall planning, but data collection also has low normalization and authenticity has no effective guarantee. At the same time, the content of the bank customer information management system is relatively short lag, and is lacking of scientific analysis method and means.

\section{DATA MINING}

Data mining is also called Knowledge Discover in Database (KDD for short). KDD was firstly used on the 11th International joint artificial intelligence conference in August of 1959.

The generalized definition of data mining is to extract nontrivial, implicit and unknown information with potential using value from the large amount of data. And the narrow definition of it is just a process of KDD. The whole processes of KDD include data selection, data preprocessing and data cleaning, data mining, knowledge assessment and other steps. Data mining is just a process to deal with the data and extract knowledge from it after preprocessing. The definition process of data mining process is described as below which is shown in the definition process of data mining in Fig.1: 


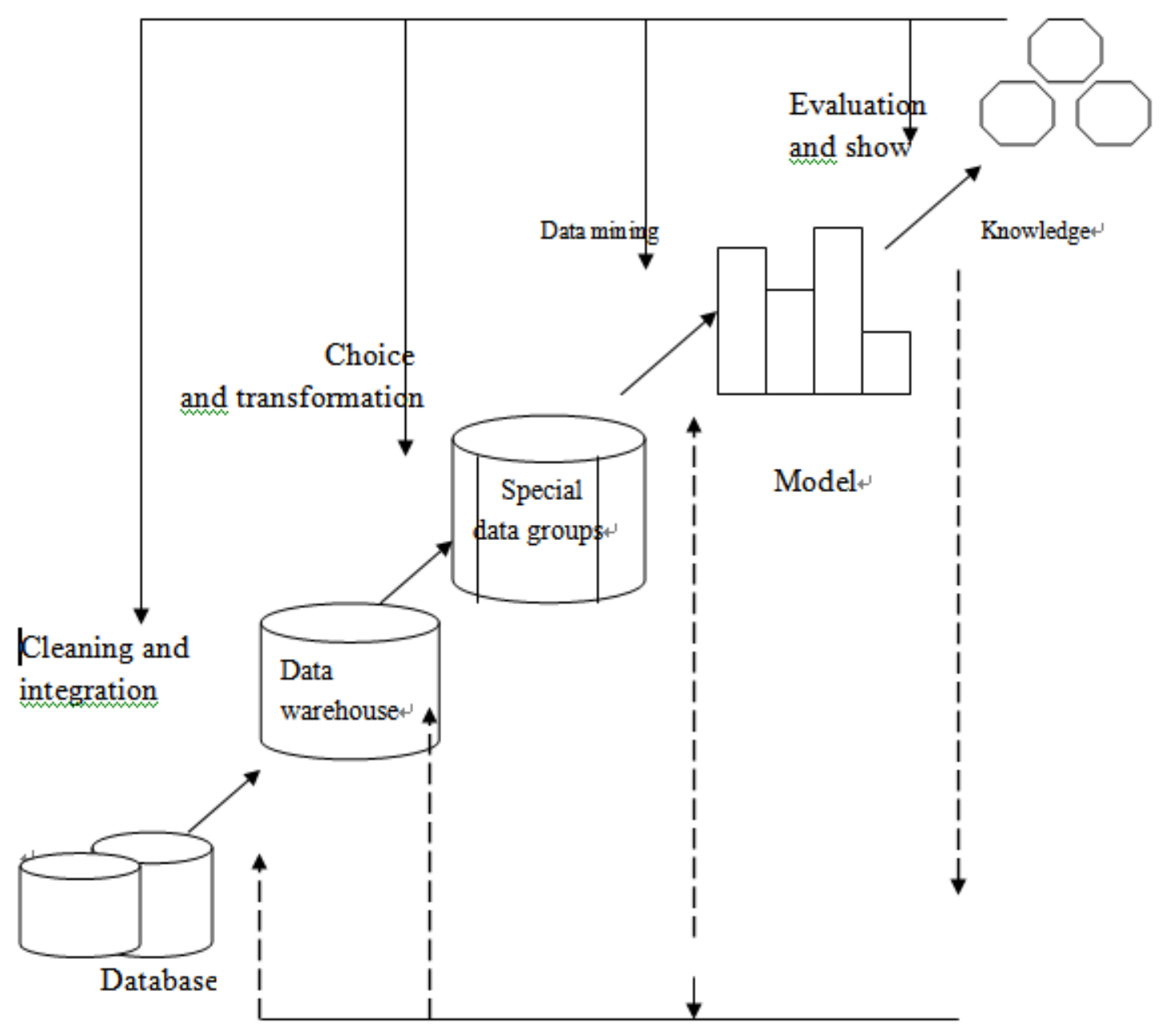

Figure 1.The definition process of data mining

As it can be seen from Figure 1, the whole process of knowledge discovery is composed of a number of mining steps, and data mining is only one of the main steps. The main steps of KDD are:

Data cleaning, the role of which is to clear data noise and the data which obviously has no relationship with mining subject;

Data integration, the role of which is to collect the related data from multiple data source;

Data choice, the role of which is to extract and analyze the date related to tasks;

Data transformation, the role of which is to transfer data into the storage forms which is easy for data mining;

Data mining is a basic step of knowledge mining. Its role to mine data model or rule knowledge using the method of intelligent.

\section{THE OVERALL DESIGN OF THE SYSTEM OF THE DATA} MINING IN BANK PERSONAL HIGH QUALITY CUSTOMERS

Bank personal quality customer management system based on data mining is mainly using the modern advanced data summary and analysis and mining tools to conduct in-depth analysis and mining to the large amount of data, establish related model and mainly complete the personal customers segmentation based on the comprehensive contribution to banks of personal customers. Its achievement is mainly based on customer segmentation. It distinguishes the high quality customers, general customers and low quality customers by their characteristics. Especially for high quality customers, banks should pay close attention to them in the change and satisfaction in banking products and service demands. According to different demands, banks shall provide them with corresponding service, 
thus improve their satisfaction of banking products and services and the loyalty of banks. According to the purpose and requirements to achieve bank personal high quality management system based on data mining, the system can be divided in three function module, which is shown in Fig .2:

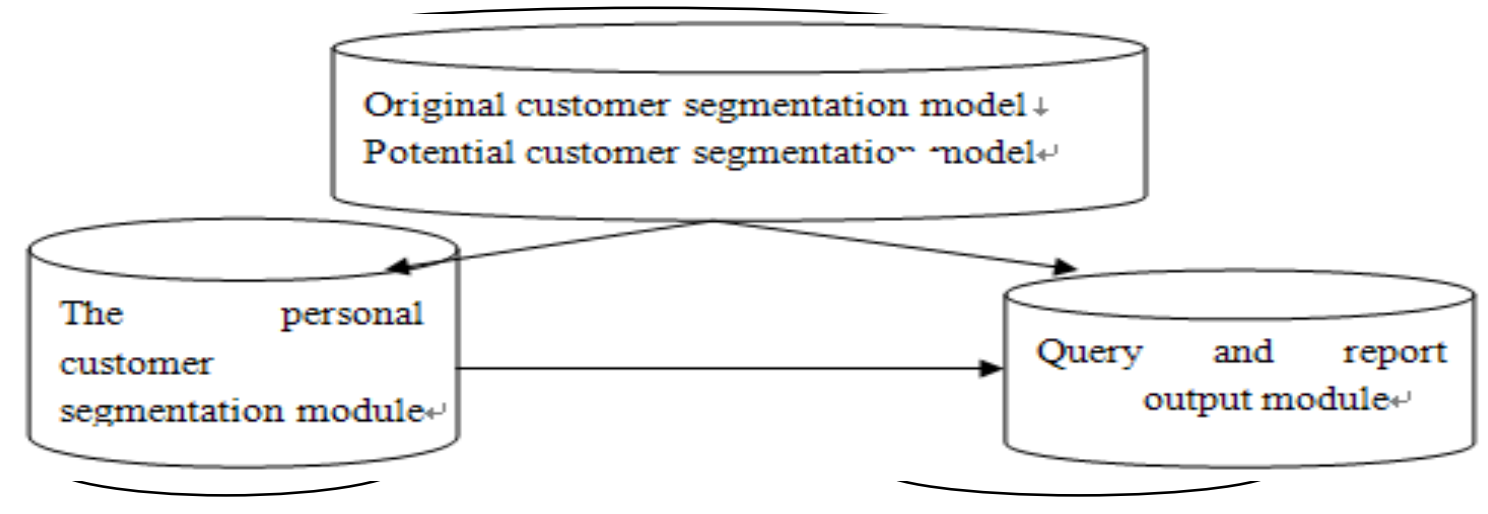

Figure 2. Distribution of system module

The first function module is data mining stage which is to establish personal customer segmentation model using data mining related algorithms; the second function module is subdividing bank personal customers. The two small modules between them are respectively the original personal customer segmentation and the potential personal customer segmentation; the third function module is the system query and report forms printing module. There is mutual contact compliance among the three modules. The development of the later module always depends on the basis of the realization of the former one.

\section{CONCLUSION}

The market of personal customers of banks is more and more big, the real personal customer managers for the personal customer service in commercial banks are relatively less and the services designed for personal customers are also less. General personal customers cannot be provided with one-on-one service like corporate customers in banks. Facing huge amount of personal customers, it is hard to distinguish high quality customers accounting for $20 \%$, who product $80 \%$ profits for banks. How to distinguish this part of customers in the huge amount of customers is what this paper discusses. The paper has made the following preliminary results by the research of the application of data mining in bank personal high quality customers management:

Several models of data mining are introduced, including: correlation analysis, classification and prediction, cluster analysis, etc.

In the personal high quality customer management application study, it analyzes customer classification, customer acquisition, credit analysis and the importance of keeping customers, and applies the simple problems of data mining in personal high quality customers management.

\section{REFERENCES}

[1] [1] Data C. Data Mining: Concepts And Techniques[J]. San Francisco, 2010, 29(S1): 1 - 18.

[2] [2] Hall M, Frank E, Holmes G, et al. The WEKA data mining software: an update[J]. Sigkdd Explor Newsl, 2008, 11(1):10-18.

[3] [3]Sharma, R., Shah, K., Shirahatti, Y., Patel, S., Sharma, R., \& Shah, K., et al. (2010). Data mining: concepts and techniques. Building A Data Warehouse, 32(43), 619-630.

[4] [4] Witten I H, Frank E. Data mining: practical machine learning tools and techniques with Java implementations[J]. WSEAS TRANSACTIONS On SYSTEMS KAŚPAROVÁ MILOSLAVA, KŘUPKA JIŘÍ, JIRAVA PAVEL ISSN: 1109-2777 1175 Issue 10, Volume 7, 1999, 4(4):76-77.

[5] [5]Edelstein H A. Introduction to Data Mining[J]. Retrieved April, 1999, 26(25):236-238.

[6] [6] Micheline Kamber, Han J. Data Mining: Concepts and Techniques (2nd edition) [J]. San Francisco, 2001, 5(4):1 - 18.

[7] [7]Fayyad, Usama M., G. Piatetsky-Shapiro, and P. Smyth. From data mining to knowledge discovery: an overview. American Association for Artificial Intelligence, 1996:1-34.

[8] [8] Hand D J, Mannila H, Smyth P. Principles of Data Mining, vol 1[J]. Mit Press Books, 2001, volume 30(7):621-622(2).

[9] [9]Chen M S, Han J, Yu P S. Data mining : An overview from a database perspective[J]. IEEE Trans Knowledge \& Data Eng, 1996, 8(6):866-883.

[10] [10]Chen M S, Han J, Yu P S. Data Mining: An Overview from Database Perspective[C]// IEEE Transactions on Knowledge and Data Engineering. 1996:866--883.

[11] [11]Ng R T, Han J. Efficient and Effective Clustering Methods for Spatial Data Mining[J]. Proc of the Vldb Conjerence, 1994, 88(9):144--155.

[12] [12]Berkhin P. Survey Of Clustering Data Mining Techniques[J]. Grouping Multidimensional Data, 2002, 43(1):25--71. 